\section{Leading causes of certifiable visual loss in England and Wales during the year ending 31 March 2013}

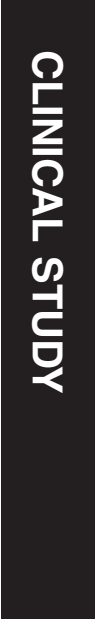

${ }^{1}$ Department of R\&D, NIHR $B R C$ for Ophthalmology, Moorfields and UCL Institute of Ophthalmology, London, UK

${ }^{2}$ Royal National Institute of Blind People (RNIB),

London, UK

${ }^{3}$ Faculty of Infectious and Tropical Diseases, London School of Hygiene and Tropical Medicine, London, UK

Correspondence: C Bunce, Research and Development, Moorfields Eye Hospital, 162 City Road, London EC1V 2PD, UK Tel: +44 (0)207 566 2820; Fax: +44 (0)207 6086925 E-mail: c.bunce@ucl.ac.uk

Received: 22 April 2015 Accepted in revised form: 18 December 2015 Published online: 29 January 2016 ratio SI:SSI has remained static with $55 \%$ of all certifications being SI. The proportion of certificates without a single main cause has fallen slightly (16.6 to $14 \%$ ). The proportion of certificates with a main cause of degeneration of the macula and posterior pole (mostly age-related macular degeneration (AMD)) decreased from 58.6 to $50 \%$ SSI and from $\mathbf{5 7 . 2}$ to $52.5 \%$ SI. Glaucoma remains the second most common cause (11\% SSI; $7.6 \%$ SI) but hereditary retinal disorders overtook diabetes as third leading cause of SSI.

Conclusion AMD is still by far the leading cause of certifications for sight impairment in England and Wales (both SI and SSI). Proportionate changes have been observed since 2008, but it is important to note that a proportionate increase in one condition will

Eye (2016) 30, 602-607; doi:10.1038/eye.2015.288; published online 29 January 2016

\section{Introduction}

The number of blind people in Britain has been counted since 1851, and reports on the causes of

\begin{abstract}
Purpose The last article on causes of sight impairment (SI) in England and Wales was for April 2007-March 2008. This report updates these figures for April 2012-March 2013. Methods In England and Wales, registration for SI is initiated by completion of a certificate of vision impairment (CVI). The main cause of visual impairment was ascertained for certificates completed April 2012-March 2013. A proportional comparison against April 2007-March 2008 was made. Results We received 24009 CVIs of which 10410 were for severe sight impairment (SSI) and 13129 were for SI. These numbers were slightly higher than those observed in April 2007-March 2008 (9823 SSI; 12607 SI). The

low vision in England and Wales began in 1950. ${ }^{1-8}$ Since 2005 in England and 2007 in Wales, registration as blind or partially sighted has been initiated by completion of a designated certificate - the Certificate of Vision Impairment (CVI) in England and the CVI-W in Wales. Copies of each form are sent for epidemiological analysis to the Certifications Office, London. The last complete report on causes of blindness in England and Wales was for data collected during 1 April 2007 and 31 March 2008. ${ }^{9}$ This is a report of an analysis conducted on all CVIs and CVI-Ws, with certification dates between 1 April 2012 and 31 March 2013, which arrived at the Certifications Office London before November 2013 (at which point the data set was locked).
\end{abstract} impact on others.
A Quartilho1, P Simkiss², A Zekite1, W Xing1, R Wormald ${ }^{1,3}$ and C Bunce ${ }^{1,3}$

\section{Materials and methods}

Methods relating to capture of data have been described in detail previously. ${ }^{10}$ Double data entry was conducted on a random sample of $2 \%$ of the forms and an error rate of $<2 \%$ established. To facilitate comparison with previous analyses and to provide information for ophthalmologists of varying specialties, we coded data using the ICD-9, 11 tabulated the number of certificates attributed to each single main cause of visual impairment and present these numbers as percentages of the total number of certificates for blindness/ partial sight. Single main cause is where the ophthalmologist indicated that that condition is responsible for sight loss. To avoid risk of disclosure figures below five are not reported. We calculated the proportion of forms in which a single cause had not been stated. Multiple causes are where the ophthalmologist did not indicate a single cause of visual loss. There may be differing causes in the two eyes or more than one cause within one eye and the ophthalmologist did not decide, which 
contributed most to certifiable visual loss. We tabulated multiple cause against age and visual status to assess whether or not this influenced the likelihood of multiple cause being recorded. We present figures for leading causes, including the number of certificates where this was the main cause of visual impairment and where a multiple cause had been recorded and that condition was a contributory diagnosis. This means that a certificate can contribute to more than one cause.

\section{Results}

We received 24009 CVI certificates in the year ending March 2013, of which 10410 were people certified with severe sight impairment (blindness; SSI) and 13129 certified with sight impairment (partial sight; (SI). A total of 22647 forms were completed in England and 1362 in Wales. An additional 470 (2\%) forms did not state whether or not the individual was SSI or SI as compared with 755 (3.3\%) of 23185 CVIs completed during April 2007-March 2008. The single main causes of certifiable SSI are shown in Table 1 . The number of forms lacking information on cause was slightly lower in the year ending 31 March 2013 as compared with the year ending 31 March 2008 (443 vs 507 forms). Figure 1a shows the relative percentages of the leading causes of certifiable SSI (where there is a single cause). The most commonly recorded main cause of certification for SSI was degeneration of the macula and posterior pole (ICD 362.5; 50\%), which largely comprises age-related macular degeneration (AMD)—both neovascular, atrophic and mixed. This presents a decrease to what was seen in 2007-2008 where the figure for AMD was $58.6 \%$. The figure for next most frequently occurring cause of blindness, glaucoma, has risen from $8.4 \%$ in 2007-2008 to $11 \%$ in $2012-2013$. SSI certifications owing to hereditary retinal disorders have risen from 5.5\% in 2007-2008 and to $8.2 \%$ in $2012-2013$, which means that hereditary retinal disorders are now the third leading cause of SSI certifications. Thus, diabetes is displaced into fourth position being responsible for $5.4 \%$ of SSI certifications in 2013 compared to $6.3 \%$ in 2007-2008. Optic atrophy $(4.9 \%)$, cerebrovascular disease $(2.7 \%)$, disorders of visual cortex $(2.6 \%)$, congenital anomalies $(2.1 \%)$, and retinal vascular occlusions $(2 \%)$ were the next frequently occurring

Table 1 Single main causes of severe sight impairment (blindness): certifications April 2012-March 2013

\begin{tabular}{|c|c|c|c|c|c|c|}
\hline \multirow{3}{*}{$\begin{array}{l}I C D-9 \\
001-139,771\end{array}$} & \multirow{2}{*}{$\begin{array}{l}\text { Codes } \\
53,130,136.1,771.0\end{array}$} & \multirow{2}{*}{$\begin{array}{l}\text { Cause } \\
\text { T: infections, congenital or acquired }\end{array}$} & \multicolumn{2}{|c|}{ Number } & \multicolumn{2}{|r|}{$\%$} \\
\hline & & & 8 & & 0.09 & \\
\hline & $190,190.5,191,239.9$ & T: all neoplasms & 55 & & 0.63 & \\
\hline & 191 & Malignant neoplasms of brain and nerve system & & 41 & & 0.47 \\
\hline & 270.2 & Albinism & & 52 & & 0.59 \\
\hline $320-326$ & $282.5,320,323,325$ & T: inflammatory diseases of the Central Nervous system & 5 & & 0.06 & \\
\hline $340-349$ & & T: other diseases of central nervous system & 16 & & 0.18 & \\
\hline 360 & & T: rest of disorders of globe & 109 & & 1.25 & \\
\hline & 360.2 & Degenerative disorders of globe & & 99 & & 1.13 \\
\hline 362 & & $\mathrm{~T}$ : other retinal disorders & 5818 & & 66.56 & \\
\hline & 362.0 & Diabetic retinopathy & & 391 & & 4.47 \\
\hline & $34000^{\mathrm{a}}$ & Diabetic Maculopathy & & 78 & & 0.89 \\
\hline & 362.3 & Retinal vascular occlusion & & 175 & & 2.00 \\
\hline & 362.5 & Degeneration of macula and posterior pole & & 4368 & & 49.97 \\
\hline & 362.7 & Hereditary retinal dystrophies (eg Ushers) & & 722 & & 8.26 \\
\hline 363 & & T: chorioretinal inflammations, scars, and other disorders of choroid & 38 & & 0.43 & \\
\hline 364 & & T: disorders of iris and ciliary body & 10 & & 0.11 & \\
\hline 365 & & $\mathrm{~T}$ : glaucoma & 958 & & 10.96 & \\
\hline & 365.1 & Open-angle glaucoma & & 816 & & 9.34 \\
\hline & 35000 & Secondary Glaucoma & & 50 & & 0.57 \\
\hline 366 & $366,366.1$ & T: cataract (excludes congenital) & 31 & & 0.35 & \\
\hline 368 & & T: visual disturbances & 13 & & 0.15 & \\
\hline $370-371$ & & T: keratitis, corneal opacity and other disorders of cornea & 129 & & 1.48 & \\
\hline & 371 & Corneal opacity and other disorders of cornea & & 121 & & 1.38 \\
\hline $372-376$ & & T: disorders of conjunctiva, eyelids and orbit & $\mathrm{b}$ & & $\mathrm{b}$ & \\
\hline 377 & & T: disorders of optic nerve and visual pathways & 730 & & 8.35 & \\
\hline & 377.1 & Optic atrophy & & 431 & & 4.93 \\
\hline & 377.4 & Other disorders of optic nerve & & 23 & & 0.26 \\
\hline & 377.7 & Disorders of visual cortex & & 228 & & 2.61 \\
\hline 378 & & $\mathrm{~T}$ : strabismus and disorders of binocular eye movements & b & & b & \\
\hline 379 & $379.50,379.51$ & T: other disorders of eye (except aphakia 379.3) & 12 & & 0.14 & \\
\hline $430-438$ & $430,431,437.1$ & T: cerebrovascular disease & 236 & & 2.70 & \\
\hline $440-459$ & & $\mathrm{~T}$ : other circulatory disease & 8 & & 0.09 & \\
\hline $740-759$ & & T: congenital anomalies & 183 & & 2.09 & \\
\hline & 742 & Other congenital anomalies of nervous system & & 51 & & 0.58 \\
\hline & 743 & Congenital anomalies of eye & & 129 & & 1.48 \\
\hline $760-779$ & Excludes 771 & $\mathrm{~T}$ : certain conditions originating in the perinatal period & 46 & & 0.53 & \\
\hline & 760 & Other congenital abnormalities & & 20 & & 0.23 \\
\hline & 33000 & Retinopathy of Prematurity & & 26 & & 0.30 \\
\hline $800-999$ & & T: injuries and accident & 23 & & 0.26 & \\
\hline
\end{tabular}

Abbreviation: T, total. a Codes in italics are not ICD-9 codes but were created for the CVI analysis. ${ }^{\mathrm{b}}$ Less than 5. 
a

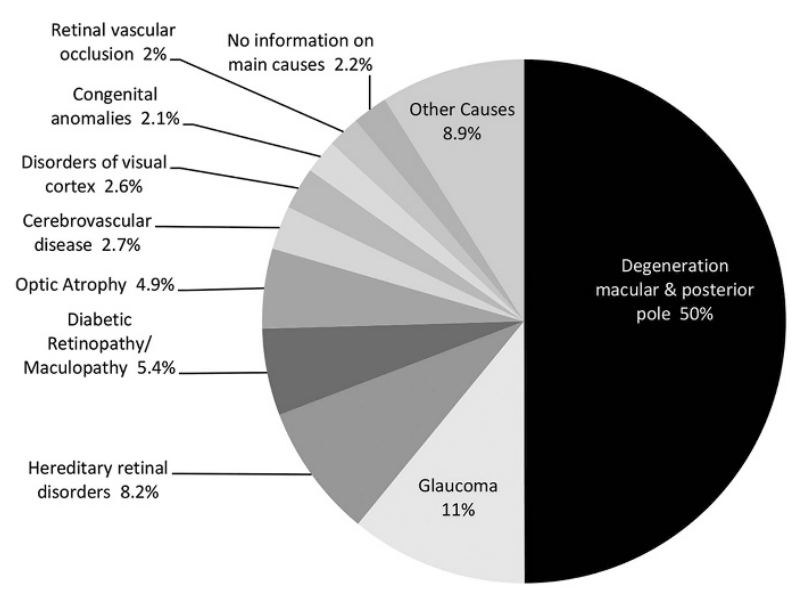

b

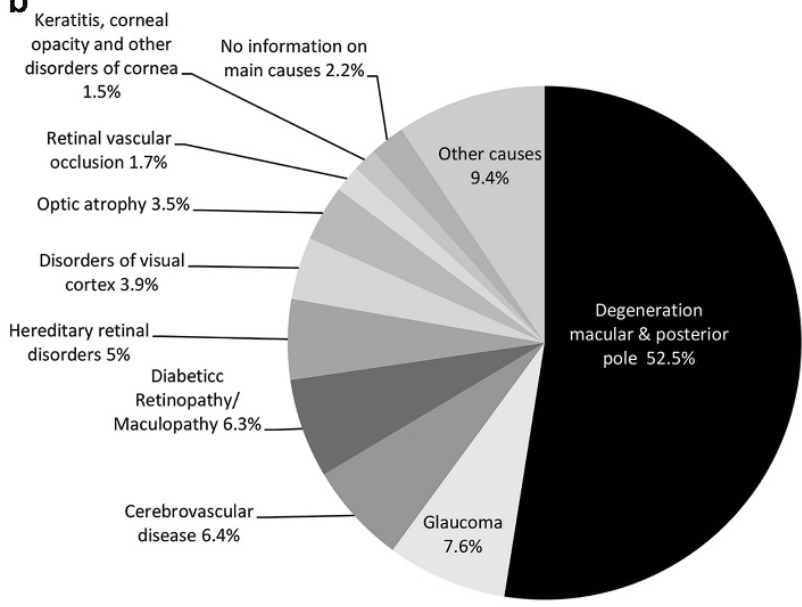

Figure 1 Main causes of (a) severe sight impairment (blindness) and (b) sight impairment (partial sight) in England and Wales: certifications April 2012-March 2013.

causes of certification for SSI, where there was a single cause.

The single main causes of certifiable SI are shown in Table 2. Figure $1 \mathrm{~b}$ shows the relative percentages of the causes of SI certification. As for SSI, the most commonly recorded main cause of certification for SI was degeneration of the macula and posterior pole (52.5\%) a decrease from $57.2 \%$ in 2008 . The next most common reported condition was glaucoma $(7.6 \%)$ as was seen also in 2008 where it was responsible for $7.4 \%$ of SI CVIs. The third leading cause of SI was cerebrovascular disease, which accounted for $6.4 \%$ of SI CVIs in contrast to it contributing to $4.9 \%$ of SI CVIs. Diabetes is displaced into fourth leading cause accounting for 6.3\% of SI CVIs as compared with $7.6 \%$ in 2008 . Hereditary retinal disorders $(5 \%)$, disorders of visual cortex $(3.9 \%)$, optic atrophy $(3.5 \%)$, and retinal vascular occlusion $(1.7 \%)$ were the next frequently occurring causes of certification for SI, where there was a single cause.

AMD, glaucoma, hereditary retinal disorders, diabetic eye disease, optic atrophy and cerebrovascular disease accounted for $82.2 \%$ of SSI certifications and the most frequently occurring causes of SI certifications (81.7\%) were AMD, glaucoma, cerebrovascular disease, diabetic eye disease, hereditary retinal disorders, and disorders of visual cortex, where there was a single cause.

In $14 \%$ of CVIs, there were multiple causes of visual impairment as compared with $16.6 \%$ of CVIs in 2008. Table 3 indicates that use of multiple cause was slightly more common in adults $(14.8 \%)$ than in children $(11 \%)$ and more common in SSI certificates $(16 \%)$ than in SI certificates (13.4\%).

Table 4 presents leading causes of certifiable sight impairment based both on single cause forms and multiple cause forms. Degeneration of the macular and posterior pole (mostly AMD) accounted for 5204 SSI forms and 6898 SI forms, with the majority of cases being due to a single cause. Glaucoma, however, occurred both as a single cause and as a contributory cause in fairly similar proportions for both SI and SSI certifications. Other causes such as Keratitis, corneal opacities and disorders of the cornea, occurred more commonly as a contributory cause than as a single cause.

\section{Discussion}

The aim of this paper is to provide updated figures on causes of certifiable vision impairment in England and Wales and to note proportional changes over a 5-year period, when the last complete analysis was reported. Any proportional comparison should be interpreted with caution as a decrease in one cause will cause a proportionate increase in other causes.

It is not surprising to see that AMD has decreased as a proportionate cause of sight impairment and this is most likely attributable to increasing availability of anti-VEGF drugs which have represented a step change in the management of neovascular AMD. Diabetes has also shown decreases as a proportional comparison and this is likely to reflect both better treatments and screening. Perhaps as a result of these changes, other conditions are emerging as prominent conditions to examine such as hereditary retinal disorders and cerebrovascular disease.

The CVI captures valuable epidemiological information on cause of sight loss but it should not be forgotten that its main function is to initiate registration as blind or partially sighted with the patients local Social Service department. Registration entitles the individual to a range of support including financial concessions and the loan of aids and equipment. A qualitative study conducted on recently 
Table 2 Single main causes of sight impairment (partial sight): certifications April 2012-March 2013

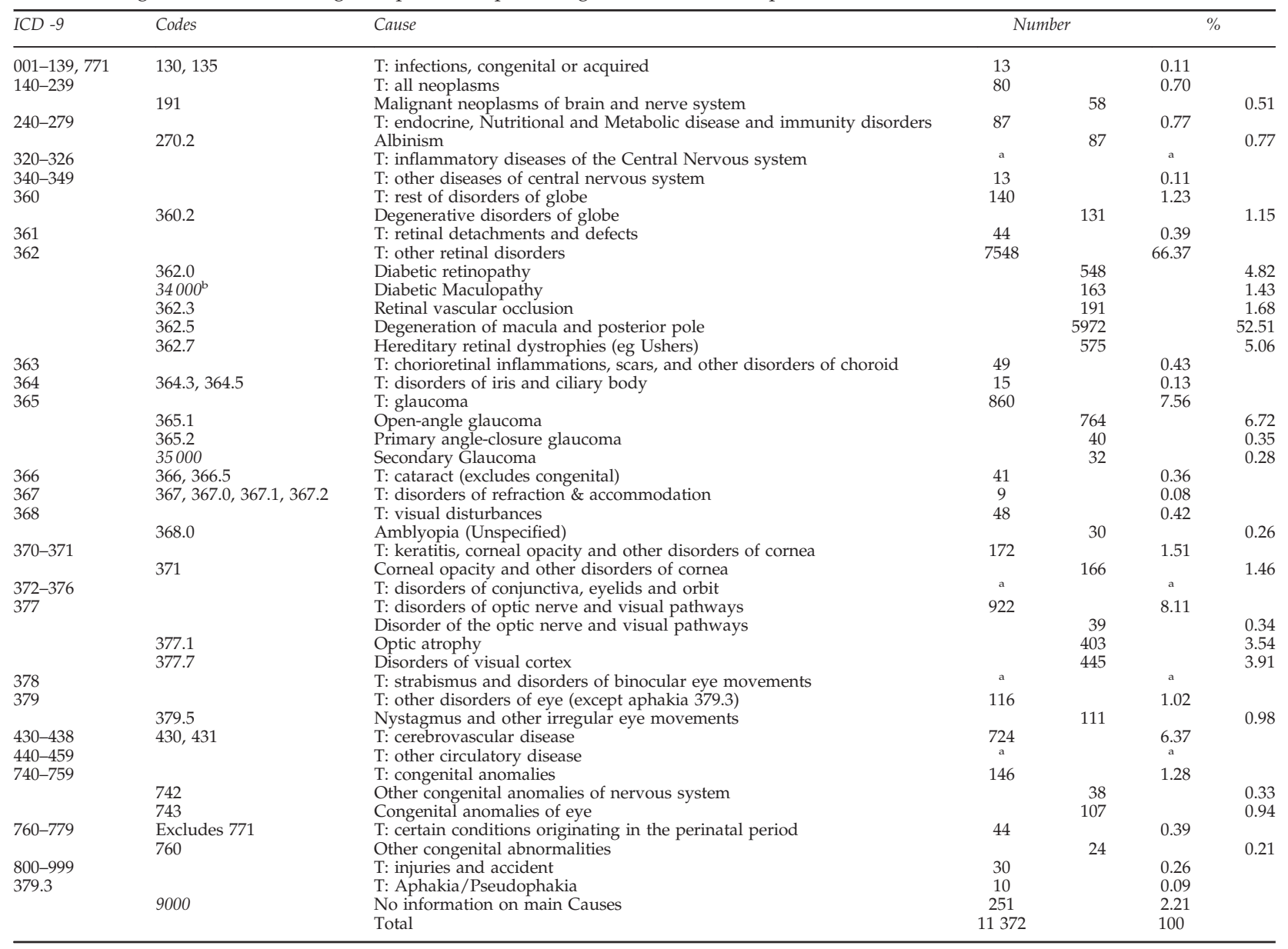

Abbreviation: $\mathrm{T}$, total. ${ }^{\mathrm{a}}$ Less than $5 .{ }^{\mathrm{b}}$ Codes in italics are not ICD-9 codes but were created for the CVI analysis.

Table 3 Prevalence of multiple causes in certifiable vision impairment by age group and certification status: certifications April 2012March 2013

\begin{tabular}{|c|c|c|c|c|c|}
\hline \multirow{2}{*}{ Study factor } & & \multicolumn{2}{|c|}{ Single cause } & \multicolumn{2}{|c|}{ Multiple cause } \\
\hline & & Number & Row \% & number & Row \% \\
\hline \multirow[t]{5}{*}{ Age at certification (years) } & $0-15$ & 1104 & 89.0 & 136 & 11.0 \\
\hline & $16-64$ & 4100 & 85.4 & 702 & 14.6 \\
\hline & $65-74$ & 2070 & 85.2 & 359 & 14.8 \\
\hline & $75-84$ & 5288 & 84.8 & 947 & 15.2 \\
\hline & 85 plus & 7820 & 85.4 & 1341 & 14.6 \\
\hline \multirow[t]{2}{*}{ Certification status } & SSI & 8741 & 84.0 & 1669 & 16.0 \\
\hline & SI & 11372 & 86.6 & 1757 & 13.4 \\
\hline
\end{tabular}

certified patients reported that while certification was a life changing event, the help they received as a result substantially improved their lives. ${ }^{12}$

It is important to note that certification figures closely reflect new registrations with local authority Social Services registers but there remains uncertainty as to how well certification data map to the actual burden of sight loss in the population. ${ }^{13,14}$ CVI data are, however, the source for the Public Health Outcome Framework indicators for sight loss in England reported annually online (CVI rates per 100k population at risk for AMD, Glaucoma, and Diabetic Eye Disease) and are also reported by the Welsh government. Patients, carers and researchers remain interested in rates for rarer conditions. ${ }^{15}$ Work is currently underway on a temporal comparison of cause using the 2013-2014 data, this 
Table 4 Numbers of SSI (blindness) and SI (partial sight) by cause, with that cause as the main cause of certifiable visual loss or with the main cause recorded as multiple but a contributory cause being that condition: certifications April 2012-March 2013

\begin{tabular}{|c|c|c|c|c|}
\hline ICD-9 & Diagnosis & Single cause & Contributory cause & Total \\
\hline \multicolumn{5}{|l|}{ SSI } \\
\hline 362.5 & Degeneration macular and posterior pole & 4368 & 836 & 5204 \\
\hline 365 & Glaucoma & 958 & 886 & 1844 \\
\hline 362.7 & Hereditary retinal disorders & 722 & 141 & 863 \\
\hline $362.0 / 34000$ & Diabetic Retinopathy/ Maculopathy & 469 & 214 & 683 \\
\hline 377.1 & Optic Atrophy & 431 & 185 & 616 \\
\hline $430-438$ & Cerebrovascular disease & 236 & 107 & 343 \\
\hline 377.7 & Disorders of visual cortex & 228 & 65 & 293 \\
\hline 362.3 & Retinal vascular occlusion & 175 & 216 & 391 \\
\hline $370-371$ & Keratitis, corneal opacity and other disorders of cornea & 129 & 211 & 340 \\
\hline \multirow[t]{2}{*}{360.2} & Myopia & 99 & 105 & 204 \\
\hline & Total & 7815 & 2966 & 10781 \\
\hline \multicolumn{5}{|l|}{ SI } \\
\hline 362.5 & Degeneration macular and posterior pole & 5972 & 926 & 6898 \\
\hline 365 & Glaucoma & 860 & 811 & 1671 \\
\hline $430-438$ & Cerebrovascular disease & 724 & 144 & 868 \\
\hline $362.0 / 34000$ & Diabetic Retinopathy/ Maculopathy & 711 & 285 & 996 \\
\hline 362.7 & Hereditary retinal disorders & 575 & 124 & 699 \\
\hline 377.7 & Disorders of visual cortex & 445 & 71 & 516 \\
\hline 377.1 & Optic Atrophy & 403 & 147 & 550 \\
\hline 362.3 & Retinal vascular occlusion & 191 & 190 & 381 \\
\hline $370-371$ & Keratitis, corneal opacity and other disorders of cornea & 172 & 204 & 376 \\
\hline \multirow[t]{2}{*}{360.2} & Myopia & 131 & 118 & 249 \\
\hline & Total & 10184 & 3020 & 13204 \\
\hline
\end{tabular}

analysis will examine change in incidence rather than proportionate changes and allow an exploration of diagnosis with age.

\section{Summary}

What was known before

- The last report on causes of certified sight loss in England and Wales was for 2007-2008. AMD was the leading cause of certification.

What this study adds

- This report updates figures on leading causes of registrable blindness in England and Wales. AMD is still by far the leading cause and glaucoma is the next frequently occurring cause of sight loss certifications followed by hereditary retinal disorders for SSI (diabetic eye disease in 2007-2008) and cerebrovascular disease and diabetic eye disease for SI (diabetic eye disease and hereditary retinal disorders in 2007-2008).

\section{Conflict of interest}

The authors declare no conflict of interest.

\section{Acknowledgements}

This study was supported by a grant from the RNIB. The posts of $A Q, A Z, W X, R W$ and $C B$ are partly funded by the National Institute for Health Research (NIHR)

Biomedical Research Centre (BRC) based at Moorfields Eye Hospital NHS Foundation Trust and UCL Institute of Ophthalmology. The data captured by the CVI are DH copyright and this work was made possible by collaboration with the Royal College of Ophthalmologists We thank Emilia Gnat and Zabed Ahmed for their support to the CVI Office. The views expressed in this paper are those of the author and not necessarily any funding body or the Department of Health.

\section{References}

1 Sorsby A. The Causes of Blindness in England 1948-1950. HMSO: London, UK, 1953.

2 Sorsby A. Blindness in England 1951-1954. HMSO: London, UK, 1956.

3 Sorsby A. The Incidence and Causes of Blindness in England and Wales 1948-62. Reports of Public Health and Medical Subjects, Vol 114. HMSO: London, UK, 1966.

4 Sorsby A. The incidence and causes of blindness in England and Wales 1963-8. Reports of Public Health and Medical Subjects, Vol 128. HMSO: London, UK, 1972.

5 Department of Health and Social Security. Blindness and Partial Sight in England 1969-76. Reports of Public Health and Medical Subjects, Vol 129. HMSO: London, UK, 1979. 
6 Government Statistical Service. Causes of Blindness and Partial Sight Among Adults in 1976-77 and 1980/81. HMSO: London, UK, 1988.

7 Evans J. Causes of Blindness and Partial Sight in England and Wales 1990-1991. In Studies on Medical and Population Subjects, Vol 57. HMSO: London, UK, 1988.

8 Bunce C, Wormald R. Leading causes of certification for blindness and partial sight in England \& Wales. BMC Public Health 2006; 6: 58.

9 Bunce C, Wormald R. Causes of blind certifications in England and Wales: April 1999-March 2000. Eye (Lond) 2008; 22(7): 905-911.

10 Bunce C, Xing W, Wormald R. Causes of blind and partial sight certifications in England and Wales: April 2007March 2008. Eye (Lond) 2010; 24(11): 1692-1699.

11 International Classification of Diseases, Ninth Revision. WHO: Geneva, Switzerland, 1977.
12 Boyce T, Leamon S, Slade J, Simkiss P, Rughani S, Ghanchi F. Certification for vision impairment: researching perceptions, processes and practicalities in health and social care professionals and patients. BMJ Open 2015; 4(4): e004319.

13 Leamon S, Simkiss P, Zekite A, Seeberan R, Bunce C. Numbers of people newly certified and registered with sight loss in England 2010-2011. Vision UK Conference 2012.

14 Malik AN, Bunce C, Wormald R, Suleman M, Stratton I, Gray JA. Geographical variation in certification rates of blindness and sight impairment in England, 2008-2009. BMJ Open 2012; 2(6): pii e001496.

15 Healthy Lives, Healthy People: Improving Outcomes and Supporting Transparency. Department of Health: UK, 2012. Available at https:/ /www.gov.uk/government/ publications/healthy-lives-healthy-people-improvingoutcomes-and-supporting-transparency (accessed April 2015). 